\title{
Professores-em-construção: reflexões sobre reposicionamento identitário em um diário dialogado
}

\section{Carla L. Reichmann}

Professora do Programa de Pós-Graduação em Lingüistica da Universidade Federal da Paraiba. Coordenadora do Grupo de Pesquisa CNPq: Retextualizando práticas, histórias e trajetórias de formadores e professores de língua estrangeira. Coordenadora do curso de extensāo CECPLIN, para professores de inglês da rede pública.

Resumo: Este artigo lança um olhar sobre um diário dialogado, focalizando a formação continuada. Ao investigar as mudanças discursivas na produção diarista de duas professoras de inglês na perspectiva da Lingüística Sistêmico-Funcional (HALLIDAY, 1994), emerge no discurso docente uma tendência semelhante em termos de reposicionamento identitário. Em suma, este artigo sublinha o impacto vital da produçāo diarista e sinaliza projetos de pesquisa em andamento.

Palavras-chave: diários dialogados; formaçáo docente; identificação
Abstract: This article addresses a dialogue journal focusing on teacher development. On exploring discursive change in a dialogue journal produced by two EFL teachers, from a Systemic Functional-Linguistic perspective (HALLIDAY, 1994) a similar trend emerges in both teachers discourse in terms of repositioning. In sum, the article highlights the vital impact of dialogue journaling in teacher education, and signals research projects in progress.

Key words: dialogue journals; teacher development; identification 


\section{Introdução}

A metáfora de paisagem [de saberes profissionais] alinha-se particularmente bem ao nosso propósito. Possibilita falar sobre espaço, lugar e tempo. Além do mais, significa expansividade e a possibilidade de ser preenchida por diversas pessoas, coisas e eventos entrelaçados em diferentes relacionamentos... Consideramos a paisagem como uma construção narrativa: possui uma história com dimensões estéticas, emocionais e éticas. A paisagem é uma história. Ao entrarmos em uma paisagem de saberes profissionais, entramos em um lugar de histórias. (CONNELLY e CLANDININ, 1999, p. 2) ${ }^{1}$.

Este artigo tem como objetivo discutir o impacto vital de diários dialogados em contextos de formação continuada de professores de língua estrangeira. Partimos das premissas que: (i) a linguagem constitui e é constituída por processos sociais, construindo identidades sociais, relacionamentos e sistemas de crenças e conhecimento (FAIRCLOUGH, 1992); (ii) aprender a construir textos e familiaridade com gêneros requer prática social (HASAN, 1989); (iii) saberes são construídos em contextos sociais, quando pessoas interagem (VYGOTSKY, 1978); e (iv) a escrita reflexiva é uma ação profissional (BURTON, no prelo). Ao problematizar as práticas discursivas do professor de língua estrangeira e sublinhar a relevância de um modelo de formação inclusivo crítico, "ou seja, um modelo que visa ao empoderamento do professor e à sua afirmação profissional" (SIGNORINI, 2006, p. 204), acreditamos que projetos de pesquisa e ensino ancorados na produção diarista podem engendrar inusitados espaços narrativos, onde o professor simultaneamente constrói seu objeto de estudo e a si mesmo, dando visibilidade ao professor-autor e às paisagens de saberes profissionais (CONNELLY e CLANDININ, 1999). Conforme apontado por Fairclough (2003, p.160), “A consciência de si mesmo é uma pré-condição para processos sociais de identificação,
1 Todas as traduções de textos citados neste artigo são de responsabilidade da autora. 
${ }^{2} \mathrm{O}$ conjunto de dados analisados neste trabalho é parte integrante do corpus da pesquisa de doutorado intitulada Reflection as social practice: an in-depth linguistic study of teacher discourse in a dialogue journal, orientada pelo Prof. José Luiz Meurer e defendida na Universidade Federal de Santa Catarina em 2001. a coñstrução de identidades sociais, incluindo a identificação social em discursos, em textos".

Este artigo apresenta um breve panorama sobre tendências recentes na área de formação de professores de língua estrangeira, discorre sobre diários dialogados e discute um estudo de caso, salientando a relevância da prática diarista em termos de reposicionamento identitário em contextos de formação docente. ${ }^{2}$ Concluindo, sublinhamos a relevância da documentação e interpretação de práticas, histórias e trajetórias de professores através da produção diarista.

\section{Sobre a formação de professores de língua estrangeira}

Divergindo de uma postura alinhada à racionalidade técnica, tendências contemporâneas na área de formação de professores de línguas convergem para práticas identitárias pautadas na complexidade, na pluralidade e na fluidez das paisagens de saberes profissionais, como podemos ver em trabalhos de Moita Lopes, 2000, 2004; Freeman, 1996, 2002; Ludke, 2001; Celani e Magalhães, 2002; Zeichner, 2002; Burton, 2005; Gimenez, 2005; Kleiman e Matêncio, 2005; Mello, 2005; Castro e Silva, 2006; Johnson, 2006 e Jordão, 2006, entre outros. Norteados por um enfoque qualitativo, os trabalhos desses educadores e lingüistas aplicados privilegiam a pesquisaação e pesquisas de cunho narrativo, etnográfico e interpretativo, problematizando temas como letramento e formação docente, o professor reflexivo, o professorpesquisador, a ética em pesquisa e construções identitárias do professor de inglês como língua estrangeira, entre outros temas.

De acordo com Johnson (2006), a recente virada sócio-cultural nas ciências humanas teve um impacto significativo no modo como a área de formação docente entende a maneira pela qual professores de língua estrangeira aprendem a profissão. Johnson (2006, p. 235) 
aponta quatro desafios inter-relacionados decorrentes dessa virada: (i) teoria/prática versus práxis; (ii) a legitimação dos saberes docentes; (iii) a reconfiguração das fronteiras de formação profissional e (iv) a formação 'localizada' de professores de língua estrangeira. Ao elaborar sobre o último ponto, Johnson (2006, p. 246) esclarece que

a formação 'localizada' de professores de língua estrangeira reconhece porque professores de língua estrangeira fazem o que fazem, imersos em contextos sociais, históricos e culturais onde seu trabalho está inserido e a partir daí se empenha em co-construir com os professores respostas localmente apropriadas às suas necessidades de formação docente.

A lingüista acrescenta que é crucial integrar em ações de formação docente as experiências prévias dos professores, suas interpretações em relação às atividades nas quais se engajam, como também seus contextos de atuação profissional. Como bem coloca Signorini (2006, p. 201),

[...] quando se pretende de alguma forma intervir nessas práticas [docentes], como no caso de cursos de formação, é preciso estar atento a essas configurações locais, específicas e fluídas de ordem institucional. E são vetores fundamentais dessas configurações locais as assimetrias de poder e saber que se constroem e se transformam nas interações sociais, tanto entre professores e agentes da burocracia estatal quanto entre, professores e seus aprendizes $[\ldots]$

Alinhando-se aos pontos acima mencionados, Gimenez (2005, p.199) sinaliza alguns desafios em relação à Lingüística Aplicada e formação de professores de língua inglesa no cenário brasileiro, tais como a definição da base de conhecimento profissional e a identidade profissional dos formadores. É relevante sublinhar, conforme coloca 
Dubar (2005, p. 33), que as identidades sociais e profissionais típicas são "construções sociais que implicam a interação entre trajetórias individuais e sistemas de emprego, de trabalho e de formação". Ancorado nesses pontos, este artigo dá visibilidade a um projeto independente de diário dialogado, quando na tentativa de promover um trabalho coerente com o que é colocado acima, uma formadora vê sua história perpassar outra história profissional. Dito de outra forma, momento em que uma formadora lança um desafio e outra professora de inglês mergulha em um diário dialogado. O diário em questão, concebido em uma disciplina de Lingüística Aplicada, vem se desdobrando continuamente em outros estudos e projetos, que serão mencionados mais adiante.

A próxima seção apresenta uma sucinta explicação sobre diários dialogados e em seguida será lançado um breve olhar sobre o estudo de caso com um diário dialogado.

\section{Sobre diários dialogados}

O diário constitui um gênero narrativo relativamente comum, abrangendo diários pessoais e diários de bordo, por exemplo, como também diários que são divulgados publicamente, como os de Anne Frank, Samuel Pepys, Katherine Mansfield e Anaïs Nin, entre outros. Mais recentemente, com o advento da Internet, verifica-se também o surgimento do diário virtual, ou "blog".

Muito utilizado em várias áreas de educação nos Estados Unidos (BAILEY, 1990; PEYTON e STATON, 2000; BURTON e CARROLL, 2001), tem sido crescente a importância do diário na área de ensino-aprendizagem de línguas no Brasil, como pode ser constatado em estudos de Liberali, 1999; Reichmann, 2001, Tápias-Oliveira, 2005 e Mello, 2005, entre outros. A pesquisa docente ancorada em narrativas de aprendizagem também pode ser realizada através de autobiografias, histórias de vida, relatos reflexivos e portfólios; ao reconstruir histórias pessoais e 
profissionais através de rememorações, ao criar sentido do presente e ao sinalizar possibilidades profissionais, a produção escrita pode ser crucial, ressignificando processos de ensino-aprendizagem de línguas estrangeiras.

Cabe aqui uma breve explicação sobre a produção diarista em contextos universitários de formação continuada, o foco deste trabalho. O diário de aprendizagem, como gênero acadêmico, é essencialmente um espaço narrativo pessoal, protegido, em que o professor/aprendiz/autor pode colocar suas dúvidas, anseios, percepções, questões, críticas, conflitos - enfim, documentar suas tensões, reflexões e (re)elaborar crenças e práticas. Colocado na posição de autor, o professor/ aprendiz constrói um espaço narrativo singular, textualizando um diálogo interior. Se esse texto é compartilhado ou não com o resto do grupo, por exemplo, de que maneira, depende de uma negociação coletiva dos participantes. Em termos de aprendizagem, conscientização e transformação, o particularmente interessante de um diário é seu aspecto longitudinal. A escrita diarista permite um valioso distanciamento crítico, possibilitando a observação e reflexão - esta afirmação é uma constante entre professores-autores. E devido ao posicionamento sempre em fluxo do leitor/autor, releituras podem ser surpreendentes.

E o que vem a ser um diário dialogado? É uma interação escrita ancorada na sala de aula - um gênero acadêmico assemelhando-se à escritura de cartas. A linguagem é informal, freqüentemente se aproximando da oralidade. O diário dialogado pode ser realizado em um caderno, ou em meio virtual. Ao criar seu próprio objeto de estudo, a documentação de discursos docentes constitui um excelente campo para pesquisa, possibilitando ao próprio professor retextualizar sua prática, utilizando sua sala de aula como espaço de formação. ${ }^{3}$ Narrativas de aprendizagem, na forma de diários, possibilitam um retextualizar da prática, de histórias e trajetórias. Os diários são aqui considerados
${ }^{3}$ Sobre o potencial de diários virtuais para pesquisa: em uma busca na Internet via a ferramenta de busca 'Google', uma busca por 'blogs docentes' resultou em 621 links. (Acesso em 26/02/ 2007). 
como gêneros discursivos que assumem uma função catalisadora do processo de ensino em curso, ou seja, que favorecem o desencadeamento e a potencialização de ações e atitudes consideradas mais produtivas para o processo de formação, tanto do professor quanto de seus aprendizes... (SIGNORINI, 2006: contra-capa).

Alinhando-se a essa definição, ou seja, considerando o diário dialogado como um gênero catalisador, a autora tem utilizado diários dialogados de formas diversas, dependendo do contexto. Por exemplo, entre pares de aprendizes, entre um grupo de aprendizes, ou aprendiz-professor. No estudo de caso em questão, o diário dialogado envolveu a autora e uma colega (doravante Lynn e Olga, nomes fictícios), que na época atuava em um curso de extensão de língua inglesa, sendo ambas alunas na pós-graduação ${ }^{4}$. Como veremos na seção abaixo, a autora assume como formadora a postura de professora-pesquisadora, ou seja, os posicionamentos de atora/analista se fundem.

${ }^{4}$ Durante o início da produção diarista, Lynn posiciona-se como doutoranda, Olga, como mestranda.

\section{Um breve olhar sobre um estudo de caso}

Conforme colocado inicialmente, a linguagem é considerada como uma forma de prática social, interligada a outros aspectos sociais (FAIRCLOUGH, 1995); neste contexto se insere o ensino de língua estrangeira, uma prática sociohistórica complexa e dinâmica. $\mathrm{O}$ foco aqui é em um estudo de caso sobre um diário dialogado produzido por duas professoras de língua inglesa cursando a pós-graduação em uma universidade pública no sul do Brasil, tendo em comum o interesse pela análise do discurso docente.

Ao textualizar suas práticas, professores podem documentar, refletir, e redirecionar suas próprias histórias, integrando a voz do professor-pesquisador e ressignificando a práxis (BARTLETT, 1990; ELBAZ, 1991; SMYTH, 1992; FREEMAN, 1996; FREIRE, 1997; 
ROMERO, 1998). Ao engajar-se na produção diarista, o profissional de linguagem se constrói discursivamente, podendo assumir o duplo papel de observador e observado, como no quadro Las Meninas de Diego Velázquez $(1656)^{5}$, onde o pintor se auto-retrata, incluindo-se, dando visibilidade ao autor. De certa forma guiada por essa imagem, na sua pesquisa de doutorado, a autora produziu um diário dialogado, visando promover um trabalho crítico-reflexivo e colaborativo, evidenciando as retextualizações de professoras-em-construção. Idealizado para gerar discurso docente para um trabalho final na disciplina Análise do Discurso Escrito, o diário tomou vida própria e estendeu-se por três semestres acadêmicos (1997.2, 1998.1, 1998.2), sendo que o aspecto longitudinal foi crucial em termos do processo de ensino-aprendizagem das professoras envolvidas, tornando-se "dados de pesquisa" alguns meses após o término da prática diarista. ${ }^{6}$

Levando-se em consideração que essa co-autoria com outra profissional foi claramente uma vivência significativa - o diário, gênero catalisador, promoveu o empoderamento docente - posteriormente esta interação foi analisada à luz da Lingüística Sistêmico-Funcional (HALLIDAY, 1994) para possibilitar uma compreensão do que ocorrera em uma dimensão lingüística. Lemke (1992, p. 85) aponta que "o universo inteiro enquadra cada enunciado, cada texto". Em outras palavras, nossas escolhas léxico-gramaticais estão atreladas às nossas histórias e "paisagens". Na perspectiva de Halliday (1994, xiv), a linguagem é sistêmica pois implica em redes de escolhas e é funcional no sentido que todo texto se desenrola em contextos de uso: a linguagem é vista como um sistema aberto e dinâmico (LEMKE, 1984), falantes criam textos que se desenrolam em contextos de uso (HALLIDAY, 1994).

Portanto, incentivada pelo impacto do diário dialogado nas práticas discursivas das duas professoras, a autora mergulhou no texto para assim entender o que
${ }^{5}$ Digitando "Las Meninas, Velazquez" na ferramenta de busca "Google", surgem várias opçōes de visualização.

${ }^{6} \mathrm{Um}$ agradecimento especial à Profa. Viviane Heberle, ministrante da disciplina, que apontou a riqueza potencial do diário dialogado como corpus. 
${ }^{7}$ É relevante

acrescentar que a autora não conhecia o construto de Halliday durante a produção diarista. fora construído discursivamente: o diário dialogado se tornou o cerne de uma pesquisa de doutorado sob uma ótica sistêmico-funcional. O objetivo principal desta pesquisa foi o de investigar as escolhas e mudanças lingüísticas no discurso docente produzido por duas professoras de inglês, Olga e Lynn, ao longo de quinze meses. Especificamente, realizou-se uma análise sistêmicofuncional através de um estudo dos sistemas de Modo e Transitividade, focalizando as relações sociais e os fazeres construídos conjuntamente?

Este artigo se detém sobre as relações sociais, investigadas através do sistema de Modo (a função interpessoal, para Halliday) - neste recorte examinando os sujeitos gramaticais realizados nos textos, focalizando os significados interpessoais textualizados, sinalizando papéis e posições. De acordo com Halliday (1994, p. 76), "o sujeito gramatical é o ponto de apoio de um argumento... responsável pelo funcionamento da oração como um evento interativo". Martin et al. (1997, p. 64) explicam que

Halliday interpreta Sujeito como uma função interpessoal, não como textual ou ideacional. Ele se aproxima do sujeito de uma perspectiva dialógica ao invés de monológica. Pode levar um tempo para lidarmos com a noção hallidayana de 'responsabilidade modal' como sendo uma característica do sujeito, mas isto é crucial para uma compreensão da categoria Sujeito na língua inglesa. (grifos no original)

O sujeito gramatical mereceu atenção especial, neste estudo de caso, devido a essa responsabilidade modal na interação. Ao contrastar a interação inicial e a final do diário, os resultados da análise revelam que, em termos de relações sociais, um aspecto semelhante emerge no discurso das duas professoras: foi detectado um aumento significativo no uso de we/let's como sujeitos gramaticais, por exemplo, 
Maybe we could videotape our classes in the beginning of the next semester, what do you think? (Olga)

Let's go ahead till we feel it is possible to go! (OIga) Maybe we can plan together? (Olga)

How can we refocus our reflective work? (Lynn)

O posicionamento das participantes se torna mais complexo e ambíguo, as posições de professora e pesquisadora tornam-se mais difusas, menos definidas como no início, quando Olga tende a se posicionar como formanda, e Lynn como formadora. Há mais simetria, construída conjuntamente. É no discurso de Olga, no entanto, que notamos uma mudança maior, um reposicionamento. Inicialmente, no discurso de Olga, o eu-professor é construído como um professor inseguro, solitário, procurando a permissão do Outro; seu texto constrói o papel de formando, designando ao Outro o papel de supervisor/formador. Na última interação, no entanto, os sujeitos gramaticais de Olga são construídos como agentes interativos e inclusivos, ocorrendo you, we e let's, como vemos nos fragmentos acima (e diferentemente do início, quando esses sujeitos simplesmente não ocorrem). O eu-professor mudou, tornou-se mais seguro e direcionado. Ou seja, através da produção textual, ocorreu uma mudança significativa no discurso docente, fortalecendo a entidade professor como sujeito, como agente. Ao longo do tempo, a função interpessoal passou a incluir mais vozes, desvelando reconstruções identitárias.

Relações de poder se baseiam em diferenças sociais: quando as professoras-autoras passam a ocupar posições mais semelhantes, as relações de poder se alteram, tendendo a mais solidariedade. Com o diálogo escrito, diminuiu a distância social e a assimetria. Como mencionado acima, as relações sociais no diário dialogado se diversificaram e se tornaram mais complexas, conseqüentemente, fica mais difícil distinguir quem é a professora, quem é a professora-pesquisadora. 
Enfim, essa análise sinalizou mudanças nas relações sociais construídas no discurso de Olga e Lynn. Para ilustrar o efeito da interação escrita, segue abaixo um fragmento de uma mensagem eletrônica de Olga enviada dezoito meses após o término da produção diarista:

Junho de 2000

Um ponto interessante é que a 'interação reflexiva escrita' parece promover uma concepção mais profunda do papel do professor no processo de ensino-aprendizagem e dos fatores que contribuem para esse processo. É como se estivéssemos construindo, através da escrita, nosso próprio objeto de estudo: nossa própria prática pedagógica e o processo de aprendizagem dos alunos é salientada. A realidade da sala de aula se torna o foco da reflexão, em oposição a fatos isolados. Lembro que no início do diário dialogado eu não sabia exatamente o que eu deveria escrever e retratava eventos isolados, parecia mais preocupada com o que eu fazia (como se eu pudesse fazer algo sozinha). Agora sou mais capaz de fortalecer a voz do aluno, sendo que eu ainda falo muito. E apesar de decidir na maioria das vezes o que vai acontecer em aula, sim, os alunos são responsáveis pela própria aprendizagem: eles sabem disso e agem de acordo... Ontem eu estava pensando como eu realmente fui treinada como uma professora-pesquisadora durante o processo do diário... é ótimo sentir todo este progresso como professora, e que realizamos isso conjuntamente. Eu realmente não sabia o que significava ser 'consciente' em relação à prática pedagógica. E não tenho mais todos aqueles medos...

Esse fragmento, produzido por Olga muito após a conclusão do diário, evidencia que seu olhar mudou, sua postura mudou: além da questão da confiança mútua e dedicação inerente a esse projeto, o aspecto temporal foi crucial no processo de aprendizagem e reposicionamento docente. Através da mediação do diário dialogado, da sua 
produção e interpretação, foi verificado que as relações sociais e posicionamentos constituem e são constituídas pela linguagem. A seguir, serão relatados alguns desdobramentos desse estudo sobre um diário dialogado.

\section{Considerações finais}

Este artigo discutiu a relevância da produção diarista em contextos de formação de professores $e$ elaborou brevemente sobre uma pesquisa de doutorado alicerçada em um diário dialogado, focalizando o reposicionamento e empoderamento profissional. Ao documentar, problematizar e complexificar a prática discursiva docente, verificou-se que as relações sociais entre as duas professoras se tornaram mais simétricas decorrência de processos sociais de identificação, ou seja, a construção de identidades sociais, em discursos e textos (FAIRCLOUGH, 2003).

$\mathrm{Na}$ introdução, foram apontados alguns desafios relativos à complexidade e pluralidade de variáveis envolvidas na formação de professores, sublinhando os desafios relativos à identidade profissional dos formadores (GIMENEZ, 2005) e à formação docente localizada (JOHNSON, 2006). Alinhando-se a esses desafios, na pesquisa de doutorado descrita acima podemos observar o impacto vital da produção diarista, catalisando ações e atitudes consideradas mais produtivas para o processo de formação de professores (SIGNORINI, 2006).

Entre outros desdobramentos desse estudo, na UFPB, organizou-se recentemente o grupo de pesquisa $\mathrm{CNPq}$ Retextualizando práticas, histórias e trajetórias de formadores e professores de $L E$, sublinhando o impacto vital da prática escrita, da mediação (VYGOTSKY, 1978) e de comunidades de prática (LAVE e WENGER, 1991) em contextos de formação de professores de língua estrangeira. Esse grupo de pesquisa cria interfaces entre ensino, pesquisa e extensão, incluindo alunos da graduação e da pós-graduação que atuam, por exemplo, em um 
projeto de formação docente para professores de língua inglesa da rede pública de João Pessoa (REICHMANN e OLIVEIRA, 2006). Narrativas de aprendizagem docente, o foco do grupo de pesquisa, têm sido produzidas por vários participantes.

Enfim, este artigo dá visibilidade à pesquisa docente engajada com a formação de professores de língua estrangeira, entendendo que a reflexão-sobre-a-ação como uma prática discursiva sistemática pode sinalizar o reposicionamento identitário - como o de professorpesquisador - e a reconstrução de paisagens de saberes profissionais, assim como nesse estudo de caso, indicando que o diário dialogado pode ser uma ferramenta viável em intervenções pedagógicas. Visualizamos a produção diarista como um caminho possível em processos de renovação profissional, (re)imaginando e iluminando a vida na sala de aula. Concluindo com as palavras de Pimentel (1994, p. 34) sobre professores-em-construção,

[h]á os que rompem com o conceito moderno de ciência e conhecimento. Partem, através da crítica e da criatividade, para a construção de novas formas de ensino. Criam seus próprios paradigmas emergentes, pós-modernos, simultaneamente científicos e sociais...Concebem o conhecimento como processo, 'espaço conceitual', no qual professores e alunos constroem um saber novo, produto sempre contraditório de processos sociais, históricos, culturais, psicológicos... Vivem a crise pela qual passa o mundo, imersos nele, atentos, em especial, para as coisas da educação. Os verbos que mais aparecem nos seus discursos são: questionar, mudar, procurar, descobrir, inventar, modificar, melhorar, sentir, participar, arriscar, inovar... Para tanto é preciso tolerar a ambigüidade, a transitoriedade, a insegurança, a solidão... 


\section{Referências}

BAILEY, Kathleen. The use of diary studies in teacher education programs. In: Jack RICHARDS e David NUNAN (orgs.). Second language teacher education. Cambridge: Camoridge Unskersity Press, 1990. p. 215-226.

BARTLETT, Leo. Teacher development through reflective teaching. In: Jack RICHARDS; David NUNAN (orgs.). Second language teacher education. Cambridge: Cambridge University Press, 1990. p. 202-214.

BURTON, Jill. Getting to the heart of teaching. In: BURTON, Jill; QUIRKE, Phil; REICHMANN, Carla (orgs.), Reflective writing - ways to lifelong teacher learning, no prelo. The importance of teachers writing on TESOL. TESLEJ, v.9, n 2, p.1-18, 2005.

BURTON, Jill; CARROLL, Michael. (orgs.). Journal writing. Alexandria, VI: TESOL Inc, 2001.

CASTRO, Solange T. Ricardo; SILVA, Elisabeth Ramos da. (orgs.). Formação do profissional docente: contribuições de pesquisas em lingüística aplicada. Taubaté, SP: Cabral Editora e Livraria Universitária, 2006.

CELANI, Maria Antonieta Alba; MAGALHÃES, Maria Cecília. Representações de professores de inglês como língua estrangeira sobre suas identidades profissionais. In: MOITA LOPES, L.P.; BASTOS, L.C. Identidades: recortes multi e interdisciplinares. SP: Mercado de Letras, 2002. p.319-338.

CONNELLY, F.Michael; CLANDININ, D. Jean. Shaping a professional identity: stories of educational practice. New York: Teachers College Press, 1999.

DUBAR, Claude. A socialização:construção de identidades sociais e profissionais. São Paulo: Livraria Martins Fontes Editora, 2005.

ELBAZ, Freema. Research on teacher's knowledge: the evolution of a discourse. Journal of Curriculum Studies 23, (1), 1-19, 1991.

FAIRCLOUGH, Norman. Analysing discourse: textual analysis for social research. London and New York: Routledge, 2003. 
. Media discourse. London: Edward Arnold, 1995.

1992.

. Discourse and social change. Cambridge: Polity Press,

FREEMAN, Donald. The hidden side of the work: Teacher knowledge and learning - a perspective from North American educational research on teacher education in English language teaching. Language teaching, 35, p.1-13, Cambridge University Press, 2002

. Redefining the relationship between research and what teachers know. In: BAILEY, Kathleen, NUNAN, David (orgs). Voices from the language classroom. Cambridge: Cambridge University Press, 1996. p.88-115.

FREIRE, Paulo. Pedagogia da autonomia. Rio de Janeiro: Editora Paz e Terra, 1997.

GIMENEZ, Telma. Desafios contemporâneos na formação de professores de línguas: contribuições da Lingüística Aplicada. In: FREIRE, Maximina; ABRAHÃO, M. Helena; BARCELOS, Ana M. (orgs.). Lingüística aplicada e contemporaneidade. São Paulo, ALAB/ Campinas, SP: Pontes Editores, 2005. p.183-201

HALLIDAY, Michael A.K. An introduction to functional grammar. London: Edward Arnold, 1994.

HASAN, Ruqaiya. Part B. In: HALLIDAY, Michael A.K.; HASAN, Ruqaiya (orgs.). Language, context, and text: aspects of language in a social semiotic perspective. Oxford: Oxford University Press, 1989. p. 52-118.

JOHNSON, Karen. The sociocultural turn and its challenges for second language teacher education. TESOL Quarterly, vol.40, no.1, março de 2006.

JORDÃO, Clarissa M. O Ensino de Línguas Estrangeiras: de código a discurso. In: VAZ BONI, Valéria. Tendências contemporâneas no ensino de línguas. União da Vitória: Kaygangue, 2006.

KLEIMAN, Angela B.; MATÊNCIO, Maria de Lourdes M. (orgs.). Letramento e formação do professor: práticas discursivas, representações e construção do saber. Campinas-SP: Mercado de Letras, 2005. 
LAVE, J.; WENGER, E. Situated learning: legitimate peripheral participation. Cambridge: Cambridge University Press, 1991.

LEMKE, Jay L. Interpersonal meaning in discourse: value orientations. In: DAVIES, M.; RAVELLI, L. (orgs). Advances in systemic linguistics: recent theory and practice. London and New York: Pinter Publishers, 1992. p. 82-104.

- Semiotics and education. Toronto Semiotic Circle Monographs, Working Papers and Prepublications. Tolollo: Victoria University, 1984.2

LIBERALI, Fernanda. O diário como ferramenta crítica. Tese de doutorado inédita. LAEL, PUC-SP, 1999.

LUDKE, Menga. O professor, seu saber e sua pesquisa. Educação e sociedade, ano XXII, n 74, 2001.

MARTIN, Jim R.; MATTHIESSEN, Chris; PAINTER, Claire. (1997). Working with functional grammar. London and New York: Arnold, 1997.

MELLO, Dilma Maria de. Histórias de subversão do currículo, conflitos e resistências: buscando espaço para a formação docente na aula de língua inglesa do curso de Letras. Tese de doutorado inédita, PUC-SP, 2005.

MOITA LOPES, Luiz Paulo Contemporaneidade e construção de conhecimento na área de estudos lingüísticos. SCRIPTA, Belo Horizonte, v.7, o 14, p. 159-171, 2004.

. Oficina de lingüística aplicada. São Paulo: Mercado de Letras, 2000.

PEYTON, Joy Kreeft; STATON, Jana. Dialogue journal bibliography Disponível em: http://www.cal.org/caela/ esl_resources/bibliographies/Dialogj.html. Acesso: 22 de março de2007. Washington, DC: Center of Applied Linguistics, 2000.

PIMENTEL, Maria da Glória. O professor em construção.

Campinas-SP: Papirus Editora, 1990.

REICHMANN, Carla Lynn. Reflection as social practice: an indepth linguistic study of teacher discourse in a dialogue journal. Tese de doutorado inédita. PGI, UFSC, 2001. 
REICHMANN, Carla Lynn; OLIVEIRA, Alessandra Meira de. Reflexões sobre (con)textos e (per)cursos de formação docente. Anais da XXXI Jornada Nacional de Estudos Lingüísticos, CDROM GELNE. J. Pessoa: Editora Idéia, pp. 3139-3144, 2006. ROMERO, Tania Regina de Souza. A interação coordenadore professor: um processo colaborativo? Tese de doutorado inédita, LAEL, PUC-SP, 1998.

SIGNORINI, Inês. (org). Gêneros catalisadores:letramento e formação do professor. São Paulo: Parábola Editorial, 2006.

SMYTH, J. Teachers' work and the politics of reflection. American Educational Research Journal, 29, (2), 1992.

TÁPIAS-OLIVEIRA, Eveline Mattos. A identidade profissional do professor e sua prática diarista. In: KLEIMAN, Angela B.; MATÊNCIO, Maria de Lourdes Meirelles. (orgs.). Letramentoe formação do professor: práticas discursivas, representações e construção do saber. Campinas: Mercado de Letras, 2005.

VYGOTSKY, Lev. Mind in society: the development of higher psychological processes. Orgs.: COLE, M.; JOHN-STEINER, V.; SCRIBNER, S.; SOUBERMAN, E. Cambridge: Harvard University Press, 1978.

ZEICHNER, Kenneth M. Educating reflective teachers for learner-centered education: possibilities and contradictions. Artigo para palestra proferida na UEL, Londrina, 2002. 